\title{
Los problemas emocionales derivados de la traducción de Pour un tombeau d'Anatole de Stéphane Mallarmé, traducido al español por Mario Campaña
}

\author{
AnABel GalÁN-MaÑAS
}

Universitat Autònoma de Barcelona Isabel.galan@uab.cat

Recibido: 18 de marzo de 2013

Aceptado: 6 de febrero de 2014

\section{RESUMEN}

En este artículo presentamos algunas de las dificultades a las que tuvo que hacer frente Mario Campaña al traducir al español Pour un tombeau d'Anatole, de Stéphane Mallarmé. Nuestro objetivo es romper con la escasa importancia que se le otorga al traductor, al que generalmente no se tiene en cuenta y se le considera como una caja emocionalmente vacía.

Mario Campaña se enfrentó a los problemas de un libro inacabado en el que el dolor por la muerte de un hijo es el eje central y tuvo que tomar decisiones estratégicas de diferentes aspectos lingüísticos. No obstante, el traductor tuvo que hacer frente, sobre todo, a los problemas emocionales derivados de la traducción de un texto literario con un contenido psicológico muy profundo y acabó sufriendo una buena parte de la angustia y el dolor infligidos por el poeta en la elegía.

Palabras clave: Traducción de poesía, problemas emocionales de la traducción; invisibilidad de la traducción; Stéphane Mallarmé; Mario Campaña.

The emotional problems arising from the translation of Pour un Tombeau d'Anatole de Stéphane Mallarmé, translated into Spanish by Mario Campaña
ABSTRACT
In this article, I present some of the difficulties arising from the translation into Spanish of Pour un tombeau d'Anatole, by Stéphane Mallarmé. My aim is to break with the insignifi- cance of translators, often considered as an emotionally empty being.
Campaña has faced several difficulties during the translation of the unfinished elegy, such as the strategic decisions related to linguistic aspects. However, the main difficulty he 
had to deal with were the emotional issues involved in the translation of a literary text of deep psychological content. He also had to deal with the anguish and the pain that Mallarmé had impregnated in the elegy. As a result, the translation had left a deep trace in Campaña, who even stated that the translation of Pour un tombeau d'Anatole had been "the deepest spiritual experience in his life".

Keywords: Translation of poetry; emotional problems in translation; translators' invisibility; Stéphane Mallarmé; Mario Campaña.

Sumario: 1. Introducción. 2. La traducción de poesía. 3. La traducción de Pour un tombeau d'Anatole. 4. Problemas formales y emocionales de la traducción de Pour un tombeau d'Anatole, de Stéphane Mallarmé. 5. Conclusiones.

\section{Introducción}

El estudio de la traducción como disciplina académica comienza a partir del mapa de traductología presentado por Holmes (1970, 1988). Holmes reconoce tres tipos principales de estudios descriptivos: los orientados al producto, los orientados al proceso y los orientados a la función. La palabra traducción se refiere tanto a la disciplina, como al producto y al proceso. Como apunta Franzoni-Moldavsky (2011), la intención de Holmes, al proponer la expresión "estudios de traducción" era en parte despejar la confusión que existía con respecto a si la traducción era un arte o una ciencia y si se podía estudiar con el mismo rigor y formalización que las matemáticas, por ejemplo. Por ello, Holmes no se interesó únicamente por darle un nombre a esta rama del saber, sino que intentó asimismo definir:

el alcance y la estructura de la disciplina. En tal sentido, ubicó los estudios de traducción en el área de las humanidades y los definió como una disciplina empírica, es decir, basada en la observación sistemática de objetos de estudio auténticos. Los dos objetivos básicos de los estudios de traducción serían, por lo tanto, la descripción de los fenómenos del traducir y la traducción tal como se manifiestan en el mundo de nuestra experiencia, y el establecimiento de los principios generales necesarios para explicar y predecir tales fenómenos.

Según Holmes, es posible que al perfeccionarse las técnicas de análisis y descripción de procesos mentales complejos se llegue a saber más sobre el proceso de traducir y, quizás, a desarrollar una psicología de la traducción. En todo caso, en este artículo pretendemos ir más allá de la psicología de la que hablaba Holmes, ya que no se trata solo de una psicología cognitiva en el sentido de estudio de los mecanismos básicos y profundos por los que se elabora el conocimiento como la percepción, la memoria, el aprendizaje, el razonamiento lógico y cuya finalidad es almacenar, recuperar, reconocer, comprender, organizar y usar la información recibida a través de los sentidos. La psicología que tratamos de sugerir es la emocional, es decir, el proyecto que acometemos en este artículo es hacer visibles y notorias las emociones y los estados afectivos que experimenta el traductor como reacción subjetiva al pro- 
ceso de traducción. En concreto, trataremos de algunas de las dificultades de traducción que ha presentado para Mario Campaña la traducción de Pour un tombeau d'Anatole, de Stéphane Mallarmé del original francés al español con el objetivo de romper con la escasa importancia del traductor como ser al que no se le tiene en cuenta, como ser que actúa como una caja vacía emocionalmente.

\section{La traducción de poesía}

\section{El traductor como mediador}

Todos los estudios existentes ponen de relieve la pluralidad de elementos que intervienen en el texto poético y, por lo tanto, en la traducción poética. En este sentido, la traducción ha de recrear esa pluralidad de elementos, lo cual supone transformaciones, supresiones y adiciones. De ahí que Raffel (1988) considere que la traducción es un juego de equilibrios y Etkind (1982) defina la traducción de poesía como una recreación que debe conservar la forma de un poema y cuyas leyes están definidas por el texto original y por las normas estéticas de la literatura de llegada (Hurtado 2001: 65-66).

En esta línea, si el producto final sigue siendo un poema, regido por las normas estéticas de la literatura de llegada, el traductor tiene que ser también poeta, ya que deberá escoger palabras, ritmos y rimas, y musicalidad. Pero también tendrá que ser mediador, ya que debe conocer el sentido que desea transmitir el autor, debe conocer la cultura y el momento en que se enmarca el original y hacérselos llegar al lector meta, sin que este se dé cuenta de que está leyendo una traducción y no un poema original.

Es cierto que el proceso de toda traducción comienza por la existencia previa de una obra personal, unívoca, individualizada, particular, ajena al traductor y al que este debe ceñirse con respeto escrupuloso (Osuna 1997: 416). La misión del traductor es trasladar, en la medida de lo posible, esa individualidad a otra lengua, nunca transformarla ni adaptarla.

El traductor es un mediador cultural; si se quiere, un benefactor de la humanidad, pero, por la naturaleza misma de la función que ejerce, estará siempre relegado a un segundo plano y, es ello, precisamente, lo que constituye la servidumbre y la grandeza de la traducción (Sáenz 1997: 407). Es desde ese segundo plano que el traductor intenta comunicar y no quedarse solamente con el léxico y las estructuras gramaticales, ya que esto sería una tarea muy superficial.

El traductor, y en especial el traductor de poesía, se centra en el significado, al que tienen acceso los que conocen el idioma en todos los niveles y los que saben leer poesía. No se trata de tener un buen diccionario y buscar la palabra correspondiente por equivalencia formal sino que hay que bucear en el sentimiento mismo que llevó al poeta a escribir la obra original. Hay que ir al sentimiento singular de lo vivido.

\section{La invisibilidad del traductor}

Venuti (1995) llama a esta invisibilidad un existir "en la sombra" y explica que el traductor trabaja para hacer su obra invisible, produciendo el efecto ilusorio de la 
transparencia que de forma simultánea lo enmascara como una ilusión y el texto traducido parece natural, y no traducido.

Camozzi y Rodrigues Gesualdi (2000) tratan asimismo sobre la invisibilidad del traductor y dicen que somos los mismos traductores quienes tendemos a "ningunearnos". Hatim y Mason (1995) son de la misma opinión, pero al mismo tiempo defienden que es inevitable que el texto traducido refleje la lectura del traductor, lo cual, a su vez, aleja aún más al traductor del lector.

Es por ello que el traductor, como sugieren Camozzi y Rodrigues Gesualdi (2000), debe saberse buscador de minas, rastreador de las marcas que dejaron las batallas en las que peleó el autor, a las que habrá que reemplazar por otras si no iguales, equivalentes; una vez definida la estrategia y desentrañada la trama, nos tocará rearmar las piezas, para lograr que crean que eso que están leyendo es la obra original, que les dice lo mismo y de la misma forma.

\section{La traducción de Pour un tombeau d'Anatole}

\section{Stéphane Mallarmé: el autor}

Stéphane Mallarmé es un poeta francés nacido en 1842. A los cinco años queda huérfano de madre, su padre le deja a cargo de sus abuelos para casarse de nuevo, y con ellos vive hasta que entró en un internado. Durante su adolescencia, Mallarmé ya escribe poesía bajo la influencia de Banville, Baudelaire y Poe, quizás como una forma de evasión de la dura realidad que le toca vivir huérfano de madre y abandonado por su padre, además de no tener una figura masculina como referente.

En su tierna adolescencia muere su hermana, con la que mantenía una estrecha relación, según algunos incluso incestuosa. Hasta ese momento, el contacto de Mallarmé con la vida había sido doloroso, pero a partir de ahí, tanto en su obra como en su quehacer diario, se intuye cierta agresividad, que aparece en forma de insumisión y vanidad, clásicos mecanismos de defensa contra la angustia de abandono y la depresión melancólica (Mauron 1998: 25).

Cuando nace su hijo Anatole, en 1871, Mallarmé surge de una crisis de melancolía ansiosa y tiene que tomar contacto con la realidad (Mauron 1998: 43). No obstante, el poeta se devanea constantemente con depresiones e incluso roza la demencia y la psicosis, como afirma Fretet (1946). Con la muerte de su hijo Anatole, con sólo ocho años, Mallarmé cae en un pozo de desesperación, contra la que intenta luchar pensando que su hijo no está muerto porque él no sabía que se moría, y cree que su obra hará que permanezca vivo. Es así como el fantasma de su hijo sobrevive en Una tumba para Anatole.

Autor de Herodías (1869) y La siesta de un fauno (1876), en la década de 1880 ya era el centro de un grupo de escritores franceses, entre los que se encontraban André Gide y Paul Valéry, con quienes compartió su idea sobre el verso libre y la construcción del poema alrededor de un símbolo central. Fue uno de los pioneros del movimiento Decadente francés, del que formarían parte los llamados poetas malditos. Este grupo de poetas, rechazando los valores de la sociedad, iniciaron una revolución en la poesía francesa. 
Mallarmé, según algunos autores, fue uno de los creadores del impresionismo literario. En esta línea, el poeta se traza como objetivo que el poema tenga la estructura de una obra musical. Temas y variaciones, pausas (espacios en blanco) entre imágenes es la forma que adoptan algunos de sus poemas (Ocampo 1981: 108).

\section{Pour un tombeau d'Anatole: la obra}

El libro Para una tumba de Anatole es una elegía compuesta por 202 notas inacabadas donde Stephane Mallarmé expresa el sentimiento de ausencia y de amor después de la muerte de su hijo menor a los 8 años a consecuencia de un reumatismo. El dolor por esta pérdida estaba agravado por el sentimiento de culpa de Mallarmé, ya que él mismo había padecido reumatismo y creyó haberle legado la enfermedad.

Se hace necesario poner en estos antecedentes al lector para explicar el contexto de estremecedora intimidad en el que fueron escritos los poemas, cuya intención última no era otra que la resurrección del niño. Los poemas no son un producto de su imaginación sino la materia consciente de su ser.

El título del libro hace referencia a "una tumba para el padre, que no era de tierra ni de piedra sino de Anatole, del cuerpo vacío de su hijo muerto" (Varela 2011).

A pesar de que este poema fúnebre inacabado se escribió en 1878, cuando murió el pequeño, el original, en francés, no se editó hasta 1961.

El lenguaje de la obra es abrupto, con frases desnudas, inacabadas que en algunos casos dificultan el sentido global de la frase. Auster (2005) afirma que es una obra diferente a todo cuanto haya leído jamás.

La obra fue traducida del original francés al español por Mario Campaña en 2005 , quien se ciñó impecablemente al texto. Se trata de una edición bilingüe francés/español, editada por Bassari.

Dada su carga emocional y su carácter inacabado, además de la práctica de Mallarmé de crear poemas cerrados en sí mismos, con una sintaxis experimental, la obra hace que las dificultades de traducción sean múltiples. En esta obra, se percibe a un Mallarmé en pleno impresionismo literario; él mismo había escrito que su intención no era pintar la cosa, sino el efecto que produce, por lo que los versos no debían contener palabras sino intenciones.

\section{Mario Campaña: el traductor}

Mario Campaña Avilés nació en 1959 en Guayaquil (Ecuador). Ha escrito biografías sobre Baudelaire y Quevedo, ha traducido a Mallarmé y a Baudelaire, y ha publicado diversas antologías de poesía hispanoamericana.

A Campaña le interesa el lenguaje poético como defensa de la libertad creadora y como resistencia ante la realidad. Su poesía se ve influenciada tanto por la poesía francesa (Rimbaud y Baudelaire), como por la poesía española del Siglo de Oro, pasando por Neruda. 


\section{Problemas formales y emocionales de la traducción de Pour un tombeau d'Anatole de Stéphane Mallarmé}

Se entiende como problema de traducción (Hurtado 2001: 286) aquella dificultad de carácter objetivo con que puede encontrarse el traductor a la hora de realizar una tarea traductora y que se puede clasificar en: problema lingüístico, extralingüístico, instrumental y pragmático.

Tomando la clasificación de Hurtado (2001: 288), en la traducción de Para una tumba de Anatole identificamos mayoritariamente problemas de traducción de tipo pragmático. Los problemas de tipo pragmático son aquellos que están relacionados con los actos de habla presentes en el texto original, la intencionalidad del autor, las presuposiciones, las implicaciones, así como los derivados del encargo de traducción, de las características del destinatario y del contexto en que se efectúa la traducción.

Como se mencionaba anteriormente ( $c f r$. III, a), expresar en la lengua de uno lo que ya ha sido expresado en otra es algo a la vez fácil y difícil: fácil porque la idea ya está expresada, y por tanto tiene límites, tiene principio y final, y difícil porque el traductor no puede crear de la nada, y esto incrementa la dificultad (Pliego 1997: 429). No obstante, en Para una tumba de Anatole la traducción presenta dos problemas que no contempla Pliego. Por un lado, la obra no tiene límites, es una obra inacabada y sin final y, por otro lado, el traductor debe partir no ya de la nada, sino de un silencio, una sugerencia, una intuición incompleta.

El traductor de esta obra tuvo que hacer frente a un estilo abrupto derivado de un original incompleto, si bien, el estilo, como apuntaba Mounin (1994: 53), también es traducible. Sin embargo, la mayor dificultad a la que tuvo que enfrentarse Campaña fue la fuerte carga emocional del texto original.

Veamos a continuación algunos de los problemas que se identifican en el original y cómo los ha resuelto el traductor.

\section{a) Sentidos figurados}

Estos sentidos figurados de algunas palabras están ligados al universo sentimental del hijo muerto, eje de toda la obra.

\begin{tabular}{|l|l|}
\hline \multicolumn{1}{|c|}{ TO } & \\
\hline Soleil couché & TM \\
et vent & y viento \\
or parti, et & oro ido, y \\
vent de rien & viento de nada \\
qui souffle & que sopla \\
(là, le néant & (aquí, la nada \\
? moderne) & ? moderna) \\
\hline
\end{tabular}


La palabra "or" del original puede ser traducida como "oro" y "ahora", pero en las dos acepciones se refiere al sol, al niño muerto. El traductor ha tenido que tomar una decisión ante la acepción del vocablo con que traducir el original. En este caso, Campaña optó por la palabra "oro". Como puede verse también hay espacios vacíos en los que el autor no llegó a completar la frase, seguramente posponiendo la finalización para otro momento, como es el caso de la frase entre paréntesis y del interrogante.

b) Expresiones relativas a las vivencias psicológicas

Entre las expresiones que tienen alguna relación con las vivencias psicológicas, podemos citar las siguientes:

\begin{tabular}{|l|l|}
\hline \multicolumn{1}{|c|}{ TO } & \multicolumn{1}{c|}{ TM } \\
\hline Larmes, afflux & Lágrimas, irrupción \\
le & el \\
de lucidité, mort & de lucidez, muerto \\
se revoit à & es visto otra vez \\
travers & transparente \\
\hline
\end{tabular}

Como el mismo Campaña explica, hay que olvidarse momentáneamente de los viejos hábitos de lectura anteriores, pues el pasaje exige un recorrido múltiple: "lágrimas de lucidez"; "(lágrimas) irrupción de lucidez"; "el muerto es visto otra vez"; "el de lucidez muerto es visto otra vez". Los sentidos son múltiples porque múltiples son los caminos que el padre mira, aunque todos hacen mirar al mismo lugar: las lágrimas hacen emerger la figura del niño.

c) Fragmentos de difícil entrever el sentido

\begin{tabular}{|l|l|}
\hline \multicolumn{1}{|c|}{ TO } & \multicolumn{1}{c|}{ TM } \\
\hline Les amis & amigos \\
doigt mystérieux & misterioso dedo \\
montré & señalando \\
& \\
apparus & aparecidos \\
- chassant & cazando \\
les faux & los falsos \\
- & - \\
\hline
\end{tabular}

El traductor, en estos casos, ha optado por traducir literalmente los términos del original, aun así el verbo "montré" ha sido interpretado por Campaña en sus diversos significados, optando por "señalando" que incluso ha requerido un cambio verbal, de un participio a un gerundio para resaltar y dar énfasis a la frase.

Como en el resto de la elegía, se ha optado por conservar la estructura estética espacial, conservando el discurso compacto, corto y fragmentado. Las estructuras 
sintácticas de todo el libro están presentadas de forma fraccionada, como si se tratara de la paleta de pinturas y no tanto del cuadro ya acabado, propio de la literatura impresionista en que se había inmerso el autor, teniendo que sobreentender el traductor la intención de lo intuido más que lo expresado. Como podemos ver, traducir requiere una continua toma de decisiones en función de la globalidad del texto.

\section{Conclusiones}

La mayoría de autores que han escrito sobre el acto de traducir, tratan especialmente del nivel formal, de la captación del sentido para poder trasladar el mensaje del original. No obstante, captar el sentido de un texto original, especialmente si se trata de poesía, puede tener un efecto emocional enorme en el traductor.

En relación con los problemas emocionales que puede ocasionar la traducción no hemos tenido ocasión de encontrar comentario alguno, y nos parece un fenómeno nada desdeñable, de un calado sutil alejado de las complicaciones formales y didácticas de las que los traductores solemos hablar desde las aulas a nuestros estudiantes. Estos problemas están relacionados con el traductor como persona, de los que salen ilesos los traductores automáticos por el simple hecho de no estar dotados de soplo de vida, de alma. En tanto que personas capaces de empatizar con los sentimientos del autor para comprender y poder transmitir y reconvertir a otra lengua con auténtica sensibilidad un texto, deberíamos tener en cuenta este proceso, advertir a los traductores noveles de este hecho, de este abrazo con la propia incomunicación y con nuestra esencia de personas.

Creemos que Campaña intentó respetar el estilo del propio Mallarmé, a su vez traductor; él había traducido a Edgar Poe. Mallarmé, según afirmaba Mounin (1955: 52), utilizaba el calco [del inglés] sin más pretensión que proponer algunos de los efectos sonoros de la música del original y del propio sentimiento, e intentaba crear el sentimiento de la sintaxis inglesa en francés mediante algunas construcciones propias del inglés. Campaña respeta las construcciones de Mallarmé y sus silencios, y nos presenta unos versos rotos, sin fin, que nos evocan el sufrimiento del poeta.

En la traducción del libro Pour un tombeau d'Anatole, el traductor se ha enfrentado a diversos problemas de traducción como son las decisiones estratégicas de los aspectos morfológicos, sintácticos, de decodificación de léxico, o incluso de la profundidad de los componentes semánticos teniendo que seleccionar formas equivalentes, estructuras paralelas que permitan compensar la pérdida de énfasis. Pero Campaña, sobre todo, ha tenido que enfrentarse a los problemas emocionales que conlleva la traducción de un texto literario de contenido psicológico muy profundo.

Nos consta que Mario Campaña vivió buena dosis de la angustia y el dolor que impuso el poeta en la elegía, y que la traducción dejó en él un rastro indeleble y profundo. Sumergirse en el sufrimiento para captar el alma de la poesía no deja indemne al traductor, el cual, a medida que avanza en la tarea, sufre un proceso paralelo similar al del autor. El traductor a través de la profundidad del texto entra en su propio dolor, revive su propio sufrimiento, su propia soledad, su propia muerte. Escribía el propio Campaña al preguntarle sobre el efecto que tuvo esta traducción en él: 
"No puedo decirte en un email lo que sentí y viví con esa traducción de Anatole. Fue tremendo. Quizá la experiencia espiritual más honda de mi vida”.

A raíz de esta afirmación, se nos ocurre que la ligazón entre traducción (interpretación) y psicología debería ser un campo de estudio. No en vano, el método terapéutico de algunas corrientes psicológicas se denomina interpretación.

El traductor ha de saber encontrar el equilibrio entre sumergirse en exceso en la profundidad de las aguas y la eficacia que requiere la profesionalidad, la rapidez, la pronta recuperación de las tareas.

Para acabar podríamos decir que la traducción de una obra poética intensa como Pour un tombeau d'Anatole es una de las tareas más arduas y complejas con las que puede enfrentarse un traductor. Es una tarea creativa de alto alcance, que requiere conocimientos multidisciplinares y destrezas tanto estructurales como emocionales, además de ser una oportunidad para explorar nuestro universo interior. Si leer la obra no deja indiferente, ¿qué remotas impresiones no despertará en el traductor?

\section{Referencias bibliográficas}

CAmozzi, D. y D. Rodrigues Gesualdi, «Un secreto bien guardado». Translation Journal 4 (2), 2000. [Consulta en línea: http://www.bokorlang.com/journal/12secreto.htm; $5 / 5 / 2012]$

EtKInD, E. Un art en crise. Essai de poétique de la traduction de poétique. L'Age d'Homme: Lausana 1982.

Franzoni-Moldavsky, A., Panorama de los estudios de traducción, 2011. [Consulta en línea: http://pipl.com/directory/name/Franzoni/Ada/\#; 14/3/2012]

Fretet, J., L'Aliénation poétique. J.B. Janin: París 1946.

HATIM, B. e I. MASON, Teoría de la traducción: una aproximación al discurso. Ariel: Barcelona 1995.

Holmes, J.S. Translated! Papers on Literary Translation and Translation Studies. Rodopi: Ámsterdam 1988.

Holmes, J.S. et. al. The Nature of Translation Studies. Essays on the Theory and Practice in Literary Translation Studies. Rodopi: Ámsterdam 1970.

HuRTADO, A., Traducción y traductología. Introducción a la traductología. Cátedra: Madrid 2001.

Mallarmé, S., Para una tumba de Anatole. Traducción y prólogo de Mario Campaña. Ed. Bassari: Vitoria-Gasteiz 2005.

Mallarmé, S., A tomb for Anatole. Traducción y prólogo de Paul Auster. New Directions Books: Nueva York 2005.

Mallarmé, S., Pour un tombeau d'Anatole. Éditions Seuil: Paris 1961.

Mauron, C., Mallarmé. Éditions du Seuil: París 1998.

Mounin, G., Les belles infidèles. Presses Universitaires de Lille: París 1994.

Mounin, G., Les belles infidèles. Cahiers du Sud: París 1955.

OCAMPo, E., El impresionismo: Pintura, Literatura, Música. Montesinos Editorial: Barcelona 1981 .

OsunA, F., «De la labor del traductor», en: Morillas, E. y J.P. Arias (eds.), El papel del traductor. Salamanca: Colegio de España 1997, 415-418. 
Pliego, I., «Los Compromisos del Traductor a Propósito de un Ejemplo Literario», en: Morillas, E. y J.P. Arias (eds.), El Papel del Traductor. Salamanca: Colegio de España 1997, 423-438.

Raffel, B., The art of translating poetry. Pittsburg: Pensylvania State University Press, 1988.

SAEnZ, M., «La traducción literaria», en: Morillas, E. y J.P. Arias (eds.), El Papel del Traductor. Salamanca: Colegio de España 1997, 405-414.

VAREla, E., «La máscara y el canto XII. Diccionario de Mallarmé (2)». Espacio Luke, 131, 2011. [consulta en línea: http://www.espacioluke.com/2011/Septiembre2011/ varela.html; 5/5/2012]

Venuti, L., The Translator's Invisibility. A History of Translation. Londres: Routledge 1995. 